\title{
The simulation of the service life of the rotary shaft of a centrifugal pump
}

\author{
Madina Isametova ${ }^{*}$, Rollan Nussipali ${ }^{1}$, and Aysen Isametov $^{2}$. \\ ${ }^{1}$ Satbayev University, Almaty, Kazakhstan. \\ ${ }^{2}$ IITU, Almaty, Kazakhstan.
}

\begin{abstract}
The article describes an automated calculation of such an essential part of a centrifugal pumps the rotor shaft, so the highest level CAD NASTRAN system PATRAN module was used for the analysis. The computational mechanical scheme was drawn up, the axial and radial force acting on the impeller and the pump shaft were determined. The stress for the maximum feed case are determined. The results of the automated strength calculation were used for further analysis of the service life of the rotor shaft of a centrifugal pump.

A computer technique for determining the service life of the shaft is given, taking into account the technological, mechanical conditions of operation and taking into account the projected service life equal to the lifetime of the uranium well. Using the automated MSC FATIGUE module, the number of loading cycles was determined, the service life safety factor was determined, which showed the efficiency of the pump throughout the entire operating time of the uranium well.
\end{abstract}

\section{Introduction}

The in-situ leaching of uranium accounts for about $20 \%$ of the global uranium field operations. Underground mines $(40 \%)$ and open mines (30\%) still hold leadership. However, the fact that such advanced uranium mining countries as the USA, Uzbekistan and the undisputed leader of the industry Kazakhstan give preference to the in-situ leaching indicates its significance. [1]

Pumps are one of the key elements of in-situ leaching technology: they are involved in all stages of production. That is why their quality and service life come to the first place in the selection of equipment, so breaks in work are unacceptable, as well as too few operating hours. [2]

Figure 1 shows a diagram of a multistage vertical centrifugal pump designed by our team.

In the practice of designing centrifugal pumps, dimensions are most often set not from the condition of strength and service life, but from design considerations and depending on technological capabilities. In addition, new pumps are usually designed on the basis of the tested prototypes. Therefore, when selecting sections of pump assemblies, the main importance is the calibration calculation for the strength and service life of the main structural elements such as shaft, impeller, housing, keyway or pin joint and coupling. [3]

For the designed pump, the input data was a flow of

$\mathrm{Q}=8.8 \mathrm{~m}^{3} / \mathrm{s}$, head $\mathrm{H}=19.5 \mathrm{~m}$, the rotation frequency is $\mathrm{n}=2850 \mathrm{rpm}$

Corresponding author: isametova69@mail.ru

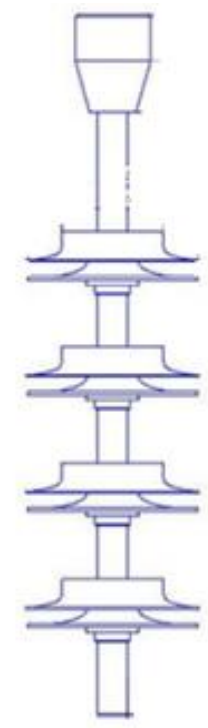

Fig. 1. Working drawing of the shaft.

In the course of long-term operation of pumps other than computational ones, the occurrence of cyclic loads, which reduce the fatigue strength of parts, is possible. With the accumulation of fatigue damage on the surface of the rotor shafts may begin the process of destruction.

Determining the causes of damage or assessing service life can be achieved by laboratory testing. 
Laboratory tests are very expensive and time consuming, since the effect of corrosion depends on time and prevents the acceleration of tests. Using computer-aided assessment methods, you can perform the same testing with the same accuracy with significantly less time and money. The best tool for assessing the fatigue strength of machine parts is MSC. Fatigue is the most advanced fatigue life evaluation program used in conjunction with calculations using the finite element method. In case of preliminary determination of the number of construction cycles before failure, you can significantly increase the product service life, as well as reduce the amount of testing required and the cost of manufacturing the first copies of the product, which ensures rapid product promotion on the market. [4]

\section{Statement of problem and research objectives}

Centrifugal pump in the course of operation perceives a number of loads that are not taken into account when carrying out traditional analytical calculations for strength and stiffness performed according to the methods most fully formulated by A. Lomakin [5]. Unfortunately, today there are no clear methods for calculating the shaft of the Centrifugal pump for strength, service life and for creating a design mechanical scheme for these types of calculations. The calculation methods outlined in the classical works of E.K. Spiridonov [6] do not provide information on the distribution of stresses and strains in the pump details.

Our purpose at the design stage of the pump was to create an adequate computer model for the strength calculation and the service life calculation of the Centrifugal pump shaft.

The service life of the shaft rotor is determined by the wear and full development of the uranium well, after six thousand hours of work they are buried. Analytical calculation of service life is carried out according to the method [7], according to which the safety factor for fatigue life of parts should be determined with respect to the design (normative) service life, the pump operating time in the amount of 6000 hours is taken as this parameter.

\section{Theoretical provisions for boundary conditions definition for computer model of centrifugal shaft service life}

For any calculation of service life, whether it is a calculation of fatigue or failure, data are required on the stress-deformable state of the model as well as input of three initial data: information about the cyclic properties of the material, loads and the geometry.

Quantitatively, the range of stresses is determined from a static calculation, for which the compilation of a design mechanical scheme was not an easy task, because today there is no clear loading scheme and the definition of forces perceived by the shaft of vertical multistage pumps for static calculation, as well as methods for determining the forces perceived by the shaft.

The forces of pressure on the impeller rotating in the pump case filled with liquid can be found according to the pressure distribution scheme presented in Figure 2 and from the considerations that the axial force acting on the pump impeller is the resultant force acting on the impeller and directed corresponding to the direction of action of the greater of these forces.
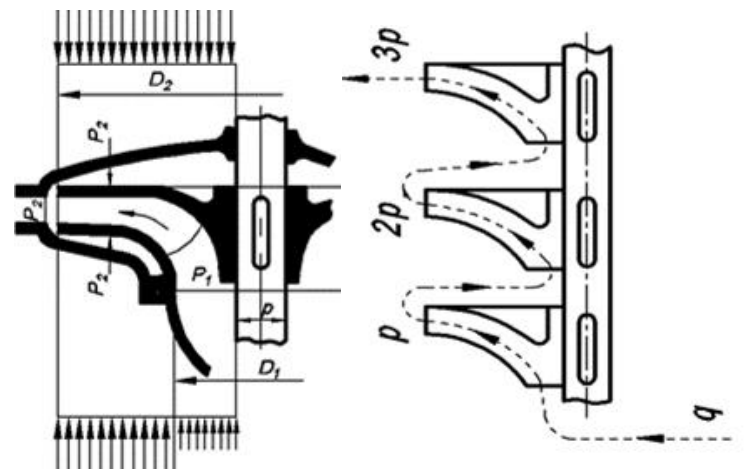

Fig. 2. Computational scheme of a) pump stages b) pressure distribution in pump stages.

The axial force can be approximately determined as the difference in pressure forces of the pumped fluid to the centrifugal wheel on from above and from below in the range from $R_{1}$ to $R_{b}$. [3]

$$
\mathrm{P}_{\mathrm{axial}}=\pi / 4 \cdot\left(R_{1}^{2}-R_{b}^{2}\right) \cdot H \cdot \gamma
$$

where $\mathrm{P}_{\text {axial }}$ - axial force in Newton

$\mathrm{R}_{1}$ is the outer radius of the inlet of the impeller in $\mathrm{m}$;

$\mathrm{R}_{\mathrm{b}}$ is the radius of the shaft in $\mathrm{m}$;

$\mathrm{H}$ - pump head in $\mathrm{m}$,

$\gamma$ is the volume weight of liquid of the liquid in $\mathrm{N}$ per meter cubic $(\mathrm{N} / \mathrm{m} 3)$.

Considering that the centrifugal pump is designed for pumping sulfuric acid with a density of $1050 \mathrm{~kg}$ per meter cubic, the value of the axial force was found.

Thus, the axial force is determined by the product of the difference between the final pressure, that the pump creates (p2) and the initial pressure at suction $\mathrm{p} 1$ multiplied by the area of the live cross-section of the flow when entering the impeller.

According to the above method, two variants of axial force were calculated, the most loaded modes for the case of zero feed: the start-up period of the machine and the maximum feed period.

Zero mode is critical because of the mounting features of the lower end of the shaft. Prior to filling the pump cavity, the system can be considered as a cantilever system, as can be seen in the diagram below. After filling the pump cavity with liquid, the free end becomes fixed in a hydrodynamic bearing, in which a thin layer of distilled medium perceives the direct load from the shaft.

Definition of radial force

The main cause of shaft deflection is radial force. For centrifugal pumps without a spiral outlet and when connecting sections with ties, radial force arises from the dynamic unbalance of the rotor. 
Determine the strength at a known residual unbalance of the wheel is possible using the following formula:

$$
R_{u}=m \cdot \mathrm{e} \cdot \omega^{2}
$$

where $m e$ is the permissible sufficient imbalance of the wheel, $\mathrm{kg} \cdot \mathrm{m}$ (for example, the expression "permissible residual imbalance of $100 \mathrm{~g} \cdot \mathrm{mm}$ " means that for a wheel with a radius of $100 \mathrm{~mm}$, external radius balancing should be performed with an accuracy of $1 \mathrm{~g}$, which is technologically achievable), $\omega-$ angular rotation speed of the pump rotor, $1 / \mathrm{s}$. the value of the eccentricities of wheels with different diameters are given in table 1. [8]

Table 1. Eccentricity with different impeller diameters.

\begin{tabular}{|l|l|l|l|l|}
\hline $\begin{array}{l}\text { Impeller outer } \\
\text { diameter, mm }\end{array}$ & $<300$ & $\begin{array}{l}300- \\
500\end{array}$ & $\begin{array}{l}500- \\
1000\end{array}$ & $\begin{array}{l}1000- \\
2000\end{array}$ \\
\hline Eccentricity, mm & 0.075 & 0.100 & 0.150 & 0.200 \\
\hline
\end{tabular}

To calculate the radial force from the imbalance, we used SolidWorks capabilities to determine the mass of a 3D model of a centrifugal wheel; these capabilities of modern CAD systems allow us to determine volumemass characteristics of any bodies of complex geometric shape (Figure 3), in our case for four wheel sections with directive vanes of mass $m=1.2 \mathrm{~kg}$.

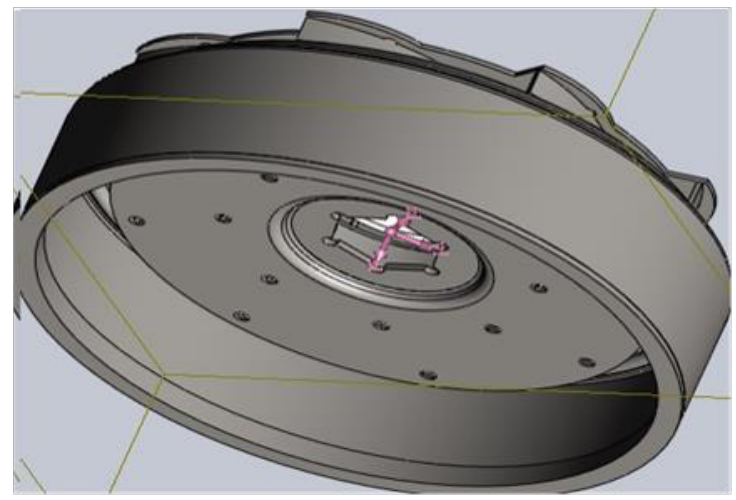

Fig. 3. Model of a centrifugal wheel in SolidWorks.

Therefore, formula (2) cannot be used, since it is given in the theory of rotor balancing, for the reason that centrifugal wheels are hollow, until they are filled with distilled medium, then to calculate the radial force in formula (2), an adjustment must be made so that the mass will be composed as the mass of the section adding the mass of the distilled liquid.

$$
R_{\mathrm{D}}=\left(m_{f}+m_{s}\right) \cdot \mathrm{e} \cdot \omega^{2}
$$

where $m_{f}$-medium mass, $m_{s}$ - centrifugal wheel section mass

The mass of sulfuric acid at a given feed was determined by the formula

$$
m_{f}=\rho \cdot \pi \cdot \frac{\left(D_{2}-D_{b}\right)^{2}}{4} \cdot b
$$

$D_{2}$-outer diameter of the centrifugal wheel, $\mathrm{m}$

$D_{b}$ - shaft diameter, $\mathrm{m}$

$b$-width of the meridian wheel section, $\mathrm{m}$ $\rho$-distilled liquid density, $\mathrm{kg} / \mathrm{m}^{3}$.

Considering the principle of superposition of forces, the radial resultant force acting on the shaft was calculated as the sum of the forces from the imbalance at each stage of the rotor.

Taking into account the scheme of pressure distribution along the centrifugal pump stages on Figure 2 , and using the above method for calculating radial and axial loads, the boundary conditions were determined.

According to the results of the calculation a table was formed with the initial data

Table 2. Input data for automated calculation.

\begin{tabular}{|l|l|l|}
\hline № & Parameter & Value \\
\hline 1 & Material & steel \\
\hline 2 & Modulus of elasticity E & $2 \cdot 10^{11} \mathrm{~Pa}$ \\
\hline 3 & Poisson's ratio & 0.3 \\
\hline 4 & $\begin{array}{l}\text { Support 1 (upper } \\
\text { support) }\end{array}$ & $\begin{array}{l}\text { Hinge with rotation around } \\
\text { the model axis }\end{array}$ \\
\hline 5 & $\begin{array}{l}\text { Support 2 (lower } \\
\text { support) }\end{array}$ & $\begin{array}{l}\text { Hinge with rotation around } \\
\text { the axis of the model and } \\
\text { moving along the vertical } \\
\text { axis }\end{array}$ \\
\hline 6 & Paxial distributed & $0.4 \mathrm{~N} / \mathrm{mm}^{2}$ \\
\hline 7 & Radial force & $290 \mathrm{~N}$ \\
\hline 8 & Type of calculation & Static \\
\hline
\end{tabular}

To simulate the transfer of load from the wheels in the form of a radial force caused by imbalance (Figure 4), the shaft was built in rigid connection with centrifugal wheels.

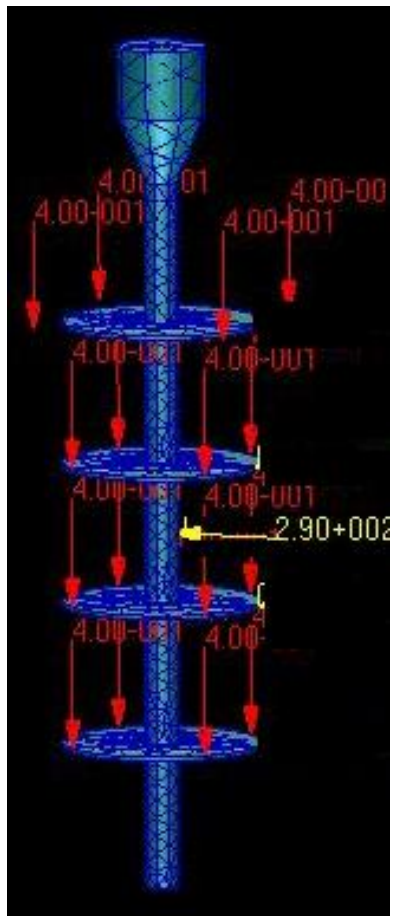

Fig. 4. Simulated computational scheme of the shaft CP.

In the PATRAN preprocessor, the shaft model was approximated by a TET MESH type finite element mesh, and as a result, 2500 elements were generated. 


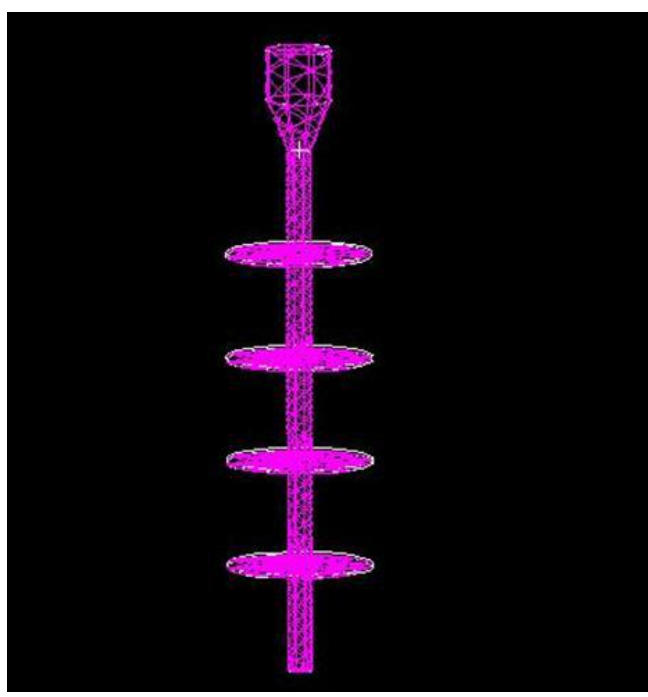

Fig. 5. Finite Element mesh.

\section{The analysis of the static calculation results}

Figures 6 and 7 show the results of the stress calculation of the CP shaft in the form of stress and displacement isolines for the case of maximum feed.

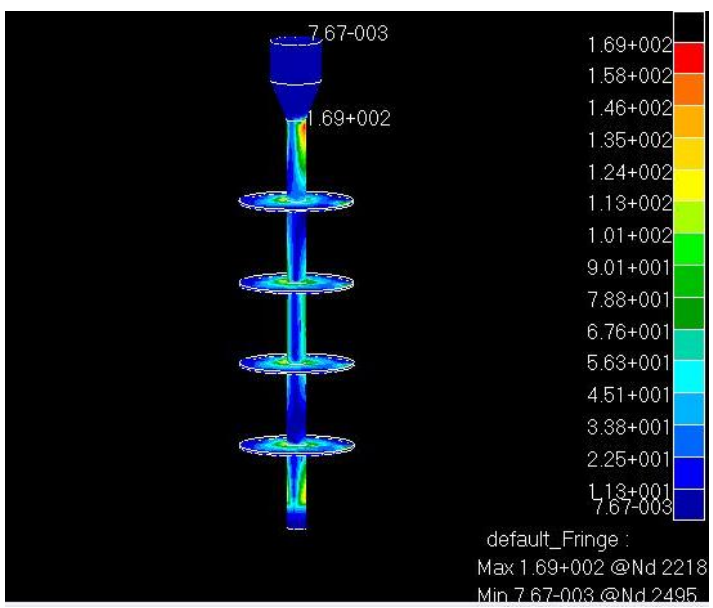

Fig. 6. Stress diagram of static calculation for maximum feed.

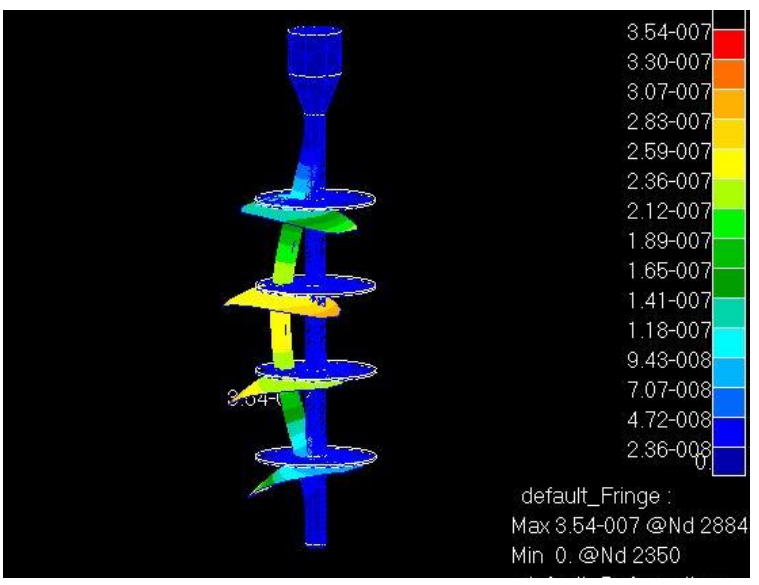

Fig. 7. Displacement diagram of static calculation for maximum feed
Analysis of the results show a sufficient safety factor for static strength at maximum feed, according to the diagram $\sigma_{-\max }=169 \mathrm{MPa}$, the allowable stress for steel $40 \mathrm{Cr}\left[\sigma_{-}\right]=680 \mathrm{MPa}$, the safety factor is $\mathrm{k}=4.02$, the maximum displacement is $7.54 \cdot 10^{-3} \mathrm{~mm}$.

The finite element model and the results of calculations of the stresses and strains were transferred to MSC FATIGUE for further analysis of the service life of the centrifugal pump shaft.

\section{Justification of method choice for shaft service life calculation}

For the fatigue calculations, one of two methods is commonly used: the first is the calculation of service life using the stress fatigue curve, or the S-N (stress-life) method, often called the total life method, which does not make difference between the appearance and development of a crack. Another method is a local deformations (local strain) method, or a service life calculation using the strain-life fatigue curve (strainlife), also called the $\varepsilon-\mathrm{N}$ method, or crack initiation method, which only considers the appearance of cracks as damage.

Structural destruction closely related to the extension of a crack after its conceiving. In addition, the life time is a combination of all aspects that affect the product service life and include many more factors than just fatigue and destruction, namely: loading conditions, environmental effects, material characteristics, simulation during testing, and more. A reliable product is the service life computational program that takes into account all these aspects (or at least the majority of them).

Based on the results of the calculation of the stressdeformable state of the shaft given above, it is possible to reasonably choose the S-N method of calculating multi-cycle fatigue, since multi-cycle fatigue occurs at stresses significantly below the yield strength $\left(\sigma_{\max }<0.6\right.$ $\left.\sigma_{0.2}\right)$. In this case, in the macro-volume the material is deformed elastically (its properties are described by Hooke's law with quite satisfactory accuracy). The duration of the stage of high-cycle fatigue by the time of the birth of the main fatigue macro crack for steel structures exceeds $10^{5}-10^{6}$ cycles. [10]

When comparing $\sigma_{\max }$ with a value of $0.6 \cdot \sigma_{0.2}$

$169 \mathrm{MPa}<320 \mathrm{MPa}$, it is obvious that the method $\mathrm{S}-\mathrm{N}$ should be chosen for the calculation of durability

\section{Shaft service life calculation modeling features}

Initial data for service life calculation are: rotor shaft material is $40 \mathrm{Cr}$ steel, $\sigma_{\mathrm{B}}=680 \mathrm{MPa}$-temporal resistance, $\sigma_{0.2}=520 \mathrm{MPa}-$ conditional yield strength, $\sigma_{-1}=460$ MPA - endurance limit, $\mathrm{m}=4$-slop of the Woehler curve, $\mathrm{N}_{\mathrm{G}}=10^{7}$ cycles(number of basic cycle;)

The coefficient of integrated accounting of design and technological factors is predetermined: $\mathrm{K}_{\sigma \mathrm{D}}=2.1$. Asymmetry influence coefficient $\psi_{\sigma}=0.2$. 
Computer calculation of the service life of the centrifugal pump shaft in the FATIGUE module was performed by the S-N method (stress-number of cycle), the method for calculating the overall service life.

In the FATIGUE system, S-N calculation is performed in the following cases.

- The task of ensuring long-term service life, when there are only small plastic deformation (plasticity), since the S-N method is based on nominal stresses.

- Cases when there is a large amount of previously obtained data on stress fatigue curves.

- Calculation of spot welding and random fluctuations, including fatigue tasks. [9]

Creating a computational model is to assign an alternating load block in the PTIME module, Figure 8 shows the cycle of the alternating load

Detailed information on load changes is extremely important to achieve an accurate prediction of service life. Loading can be defined in various ways. It can either be based on time, or on frequency, or it can be represented as different spectra depending on the type of fatigue calculations. When working with FE model the load can be applied in the form of forces, pressure, temperature, displacements or other means. Loading during testing is usually based on measurement results, most often with the help of strain sensors.

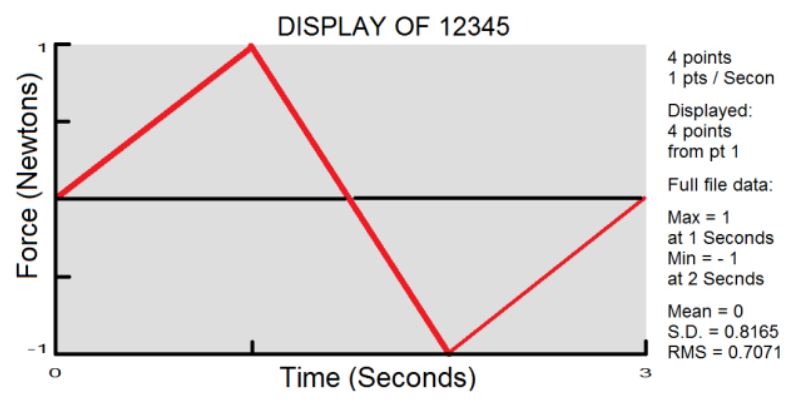

Fig. 8. Variable zero-mean Load Cycle.

Information on the material is given by the choice of the fatigue curve in the stresses and the output of the Woehler curve for the material in the form of a graph.

Materials behave differently when they are affected to cyclic (cyclic) or, conversely, static (monotonic) loading. The static properties of materials are the result of materials testing in which the load is applied statically until the test specimen is destroyed. The cyclical parameters of the material are obtained by testing, when an alternating repeated load is applied before damage at loads of different levels occurs. These parameters may vary depending on the type calculation of fatigue.

This fatigue curve, which will be used to determine the fraction of damage and, ultimately, to calculate the service life based on previously determined stresses in the model. The material from the MANTEN_MSN program database was chosen as an analogue of steel $40 \mathrm{Cr}$, the surface quality was selected as POLISHED finishing, as the impeller surface is stamped and has a class 9 roughnessRZ40-20 (Figure 9 material fatigue curve MANTEN_MSN)

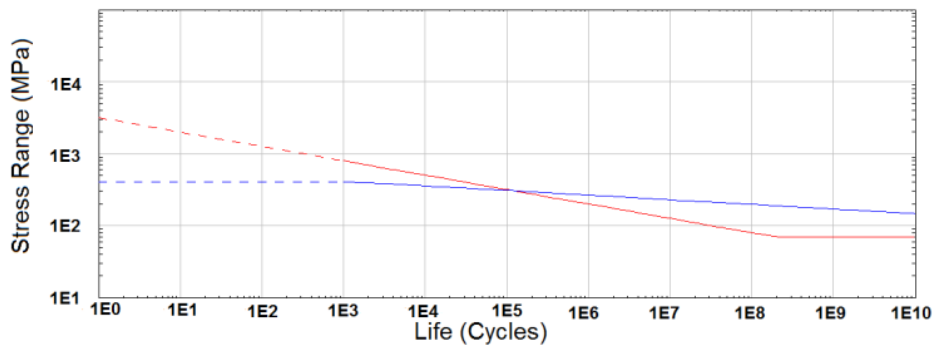

Fig. 9. Fatigue Curve of MANTEN_MSN steel (log-log).

\section{The analysis of shaft service life calculation results}

Viewing service life isolines (Figure 10) is possible in the form of Log of Life (Cycles) (log of service life (cycles)). In the diagram, the smallest service life is expressed by the number 9.08 decimal logarithm value. Due to the representation of service life values in logarithmic units, the isolines of service life give a more understandable interpretation of the calculation results.

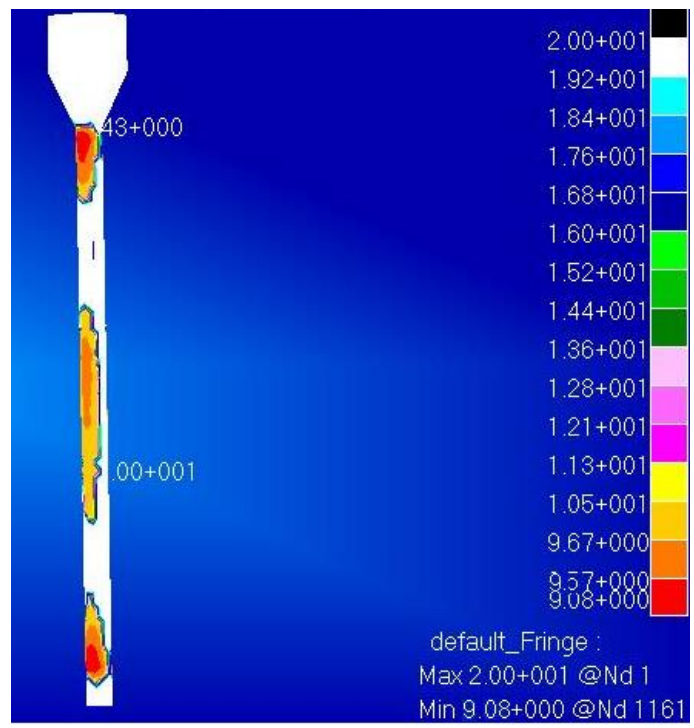

Fig.10. The results of service life calculation.

The minimal service life value at node 1 is approximately $10^{9.1}$ cycles $=1.2 \mathrm{E} 9$ cycles.

Using the formula to find the work in hours before destruction

$$
N_{\Sigma}=60 \cdot L_{h} \cdot n
$$

$N_{\Sigma}$ - the number of cycles of stress fluctuations at a constant loading mode.

where: $L_{h}$ - the number of work transfer for the estimated service life in hours;

$\mathrm{n}$-the frequency of rotation of the shaft, the material of which determines the allowable stress;

Work time before destruction is 7640 hours

The projected service life of the rotor shaft is 6000 hours, as a result of computer modeling, the lifetime of the machine is 7640 hours, therefore, the fatigue strength 
margin is 1.27.It means what pump can work before full development of the well.

\section{Conclusion}

1. The computational mechanical scheme for determining the strength of the rotary shaft of a centrifugal multistage pump was developed.

2. Methods for determining the forces acting on the centrifugal pump wheel are proposed taking into account the inertial characteristics of both the wheel section with the directive vane and the liquid being distilled.

3. According to the results of calculations made with the use of the automated MSC PATRAN module, the von Mises equivalent stress levels were $\sigma_{\max }$ is $169 \mathrm{MPa}$ and the safety factor $\mathrm{k}$ equals to 4.02 , which indicates high performance indicators of the designed machine.

4. Based on the results of the static calculation, the choice of calculation of service life by the S-N (stresslife) method was approved.

5. The method of computer calculation of the centrifugal pump shaft service life in the FATIGUE program was developed.

6. The fatigue life of the rotor shaft of steel 40Crhas been defined, the coefficient of fatigue strength of 1.27 has been determined.

7. Taking into account the technological and power conditions of operation of a multistage centrifugal pump, a computer model has been developed for determining the strength and fatigue of a rotor shaft.

\section{References}

1. www.geokniga.org A.O. Bobrovsky, Uranium mining by the method of borehole leaching (in Russian)

2. https://www.imwa.info/docs/IMWA2016 Krause Hydrological Characterization and Optimization of In-Situ Recovery Julia Krause, Jana Nicolai, Horst Märten

3. Hermod Brekke. Pumper \& Turbiner. Vannkraftlaboratoriet NTNU, (2003)

4. http://www.dissercat.com/ V.O. Lomakin Development of an integrated method for calculating flow parts of centrifugal pumps with optimization of parameters (in Russian)

5. Majan Gantar, Dr. Dussn Florjancic, Dr. Brane Sirok, "Hydraulic Axial Thrust in Multistage Pumps -Origins and Solutions", Proceedings of ASME FEDSM'01, ,pag. 1-8.I.Ya,(2001)

6. I. Berezin, O.F. Chernyavsky. Fatigue destruction of metals and calculations for strength and service life at variable strain. Tutorial. SUSU, Chelyabinsk p. 47,(2002) (in Russian)

7. A. Agostinelli, D. Nobles, C.R. Mockridge: An Experimental Investigation of Radial Thrust in Centrifugal Pumps, ASME J. Eng. Power, 80, pp. 120-126, (1960)

8. www.baltech.ru The basics of rotor balancing. Electronic textbook (in Russian)
9. MSC. FATIGUE Software Package Quick Start Guide. Translation by Ph.D. B.B. Bunin. VNIKTI Kolomna, (2007) (in Russian)

10. A.M. Vakhromeev determination of cyclic durability of materials and designs of vehicles, Methodical instructions MOSCOW, Moscow Administrative Road Inspectorate (2015)(in Russian) 